\title{
Studying Different Etching Methods Using CR-39 Nuclear Track Detector
}

\author{
Nada Farhan Kadhum, Layth Abdulhakeem Jebur, Ali A. Ridha \\ Department of Physics, College of Science, Al-Mustansiriyah University, Baghdad, Iraq \\ Email:nadaph2020@yahoo.com,li_ab_88@yahoo.com,dr.aliabdulwahab@yahoo.com
}

Received 22 April 2016; accepted 10 June 2016; published 13 June 2016

Copyright (C) 2016 by authors and Scientific Research Publishing Inc.

This work is licensed under the Creative Commons Attribution International License (CC BY).

http://creativecommons.org/licenses/by/4.0/

(c) (i) Open Access

\begin{abstract}
In this research we try to investigate the optimum etching time for the tracks originate in (CR-39) solid state nuclear track detector after irradiated with alpha source $\left({ }^{241} \mathrm{Am}\right)$ using three different etching techniques: the traditional method (water bath), microwaves and ultrasound devices. The track etching parameters: bulk etch rate $\left(V_{B}\right)$, track etch rate $\left(V_{T}\right)$, track etch rate ratio evaluates $(V)$, critical angle $\left(\theta_{C}\right)$, and etching efficiency $(\eta)$ were calculated in this research. It's seen that the optimum etching time was ranging with $(60-150 \mathrm{~min}),(20-30 \mathrm{~min})$ and $(60-120 \mathrm{~min})$ when etching with water bath, microwave and ultrasound respectively. Also we observed that the critical angle was (24.29) when etching CR-39 detector with microwave. This value is lower than the critical angles values for the detector etched with water bath or ultrasound; thus it can be the optimum magnitude because its decrease leads to increasing the number of the tracks appeared in the detector and the etching efficiency.
\end{abstract}

\section{Keywords}

Chemical Etching, Microwave, Ultrasound, CR-39, Track Etching Parameters

\section{Introduction}

Chemical etching is processes of path formation in the detector, during which a suitable etching solution attacks the detector at a sufficient speed, and the damaged regions along the ion trails (latent track) are preferentially dissolved, removed and get transformed into a hollow channel [1]. The most common etching for plastics is the aqueous solutions of $\mathrm{NaOH}$ or $\mathrm{KOH}$ with concentrations from $1-12 \mathrm{~N}$ and temperatures in between $40^{\circ} \mathrm{C}-$ $90^{\circ} \mathrm{C}$ [1]. There are several devices used for etching SSNTDs: water bath, microwave and ultrasound, and all of them provide heat to the etchant solution in addition to specific waves in microwaves and ultrasound devices which is used to speed up the etching process. The etching time is reduced and the track edges are found to be 
smooth and well defined [2].

The geometry of track etching depends on chemical etching solution along the particle track at a linear rate $V_{T}$, and a general attack on the etched surface and on the interior surface of the etched track at a lesser rate $V_{B}$ [3].

The bulk etch rate $V_{B}$ is the rate at which the undamaged surface of the detector is being removed during chemical etching. It is calculated from the equation (1) [4]

$$
V_{B}=\frac{D}{2 t}
$$

where $(D)$ is the average diameter of the track, which is measured with the use of camera supplied with a software program.

Track etch rate or the etch rate along the latent track was calculated from the equation (2) [4]

$$
V_{T}=V_{B} \frac{1+\left(\frac{V_{D}}{V_{B}}\right)^{2}}{1-\left(\frac{V_{D}}{V_{B}}\right)^{2}}
$$

where $\left(V_{D}\right)$ is the diameter rate of the tracks which can be calculated from the slope of the relation $\left(V_{D}=\Delta D / \Delta t\right)$ between track diameters and etching times.

Etching rate ratio $(V)$ is calculated from Equation (3), by dividing the average of $V_{T}$ on the average of $V_{B}$ for each case [4].

$$
V=\frac{V_{T}}{V_{B}}
$$

Critical angle of etching $\left(\theta_{C}\right)$ is determining the appearance of the etched track; it represents the minimum angle at which the etched tracks would appear on the detector surface. There is a certain critical angle for each detector types; it's calculated for all cases from Equation (4) [4] [5].

$$
\theta_{c}=\sin ^{-1}\left(\frac{V_{B}}{V_{T}}\right)
$$

Etching efficiency $(\eta)$ is the rate between the numbers of tracks etched in the nuclear track detector to the number of incident particles on it. It is calculated from Equation (5) [4] [5].

$$
\eta=1-\left(\frac{V_{B}}{V_{T}}\right)
$$

\section{Aim of the Research}

1) Estimate the optimum etching time of CR-39 detector to get both the largest track density and faster etching time when etching them chemically with the use of three different heating techniques; the conventional method (water bath), microwave and ultrasound when irradiated the detector with alpha particles.

2) Calculate the etching parameters $\left(V_{B}, V_{T}, V, \theta_{C}, \eta\right)$.

\section{Experimental Details}

\subsection{Irradiation}

Three groups of CR-39 detector Slices “(500 $\mu \mathrm{m})$ thickness supplied by Pershre Moulding LTD Co. UK.” were be cut by blade into squares of $\left(1 \times 1 \mathrm{~cm}^{2}\right)$ and exposed in air at normal incidence to alpha particles from americium $\left(\mathrm{Am}^{241}\right)$ source of $(10 \mu \mathrm{ci})$ activity for three periods of exposure $(10,20,30$ second). The main energy of the alpha particles emitted from the source was $(5.486 \mathrm{MeV}$ ) but it minimize to (3.4 Mev) by putting the detector at a distance of $(2 \mathrm{~cm})$ from the source this kinetic energy is calculated from the following experimentally 
equation:

$$
T_{\alpha}^{(3 / 2)}=R_{\alpha} / 0.318
$$

where $\left(T_{\alpha}\right)$ is the energy of alpha particle in $\mathrm{MeV}$ and $R_{\alpha}$ its range in air measured in $\mathrm{cm}$.

\subsection{Chemical Etching}

After irradiation the detectors with alpha particles they were chemically etching, chemical etching its usually carried out in thermostatically-controlled bath at temperatures ranging from $40^{\circ} \mathrm{C}$ to $70^{\circ} \mathrm{C}$, and the commonest etchant is an aqueous solution of $\mathrm{NaOH}$ or $\mathrm{KoH}$ at a molarity of from $2-6 \mathrm{M}$ and the typical etching times range from $2-6 \mathrm{hr}$.

In this research the detector was etched in $6.25 \mathrm{NaOH}$ solution by three different heating techniques; waterbath, microwave and ultrasound.

\subsubsection{Water Bath}

The detectors where be etched by putting them in etchant solution in volumetric flask putted inside the water bath tank at a temperature of $\left(70^{\circ} \mathrm{C}\right)$.

\subsubsection{Laboratories Microwaves}

It's the technique was first used at 2010 [3] where used the conventional microwave oven operating at frequency of $2.45 \mathrm{GHz}$ to speed the time of etching CR-39 irradiated by alpha particles, second it was used by at 2014 [6] [7] to etch CR-39 irradiated with fission fragments as well as by the commercially microwave oven (LG type) with frequency of $(2.45 \mathrm{MHz})$ and $(230 \mathrm{~V})$ voltage and output power of $(1300 \mathrm{~W})$.

In this research the laboratory microwave instrument shown in Figure 1 was used for the first time to etch the CR-39 detectors instead of the microwave oven, (Monowave300) type from the production company (Anton Parr) Austrian, with a frequency of $2.45 \mathrm{GHz}$ and a temperature of $70^{\circ} \mathrm{C}$ for a selected time intervals, its used by placed the etching solution and the detectors in special test tube then putting in a laboratory microwave.

\subsubsection{Ultrasound Waves}

Ultrasound is considered one of the factors which affect the properties of the SSNTDs [8] the vibration produced by the ultrasound source will excite the molecules of the detector material and the free radicals formed in the damaged regions through particle irradiations [9]. Etching with ultrasound performs by putting the detectors inside the etching solution in an ultrasound bath with a frequency of $40 \mathrm{KHz}$ and temperature of $\left(70^{\circ} \mathrm{C}\right)$.

\subsection{Viewing the Detectors}

The tracks of alpha produced in the etched detectors are viewed under an optical microscope brand N-200M with a magnification of $(400 \times)$. The microscope is connected to digital camera and computer to store the pictures of the viewing detectors.

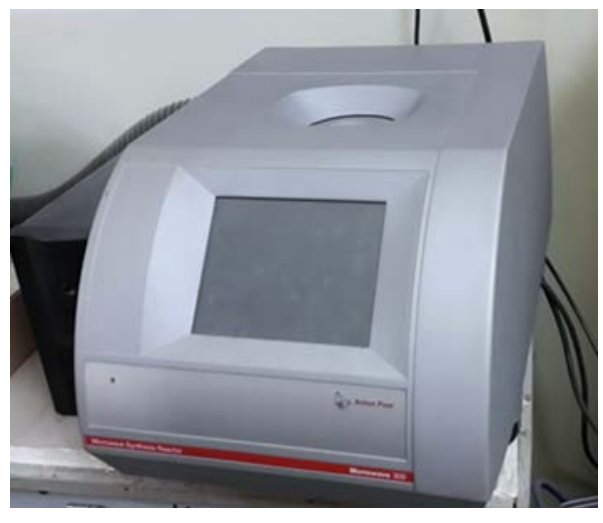

Figure 1. Laboratory microwave device. 


\section{Calculations}

\subsection{Etching Time Estimation}

The estimation of the etching time for all techniques would complete by testing various times until reaching the optimum one.

\subsubsection{When Etching with Water Bath Device}

Eight etching times were being select to test the optimum, starting from 30 to $240 \mathrm{~min}$. The utilized etching times, track densities for the three times of irradiation appeared in the detectors, in addition to their maximum and average are listed in Table 1.

The increasing of the track densities with the increasing of the etching time can be clearly observed in Figure 2.

\subsubsection{When Etching with Microwave Device}

The exercised etching times and the track densities, in addition to the maximum and average of the track densities are shown in Table 2.

The increasing of the track densities with the developing of the latent tracks and the enlarging of them against the increasing of the etching time can be clearly observed in Figure 3.

Table 1. Track densities in CR-39 detector at different doses and various etching times when using water bath device.

\begin{tabular}{cccc}
\hline & \multicolumn{3}{c}{ Track density $\left(\rho^{\text {no }} / \mathrm{mm}^{2}\right)$} \\
\cline { 2 - 4 }$($ min $)$ & $(10 \mathrm{sec})$ & Time of exposure to alpha source \\
\cline { 2 - 4 } & 637 & $(20 \mathrm{sec})$ & $(30 \mathrm{sec})$ \\
\cline { 2 - 4 } 60 & 644 & 1003 & 1846 \\
60 & 720 & 1050 & 2288 \\
90 & 732 & 1304 & 2208 \\
120 & 823 & 1367 & 2211 \\
150 & 681 & 1300 & 2122 \\
180 & 670 & 1254 & 2034 \\
210 & 654 & 1216 & 2018 \\
240 & 695.1 & 1212 & 1979 \\
Average & 823 & 1213.2 & 2163.2 \\
Max & & 1367 & 2288 \\
\hline
\end{tabular}

Table 2. Track densities in CR-39 track detector at the different doses and various etching times using microwave device.

\begin{tabular}{cccc}
\hline \multirow{2}{*}{$\begin{array}{c}\text { Etching time } \\
(\text { min })\end{array}$} & \multicolumn{3}{c}{ Track density $\left(\mathrm{No} / \mathrm{mm}^{2}\right)$} \\
\cline { 2 - 4 } & \multicolumn{3}{c}{ Time of exposure to alpha source } \\
\cline { 2 - 4 } 10 & $(10 \mathrm{sec})$ & $(20 \mathrm{sec})$ & $(30 \mathrm{sec})$ \\
20 & 654 & 1124 & 1453 \\
30 & 670 & 1247 & 1466 \\
40 & 830 & 1206 & 1683 \\
Average & 708 & 1057 & 1630 \\
Max & 715.5 & 1158.5 & 1558 \\
& 830 & 1247 & 1683 \\
\hline
\end{tabular}




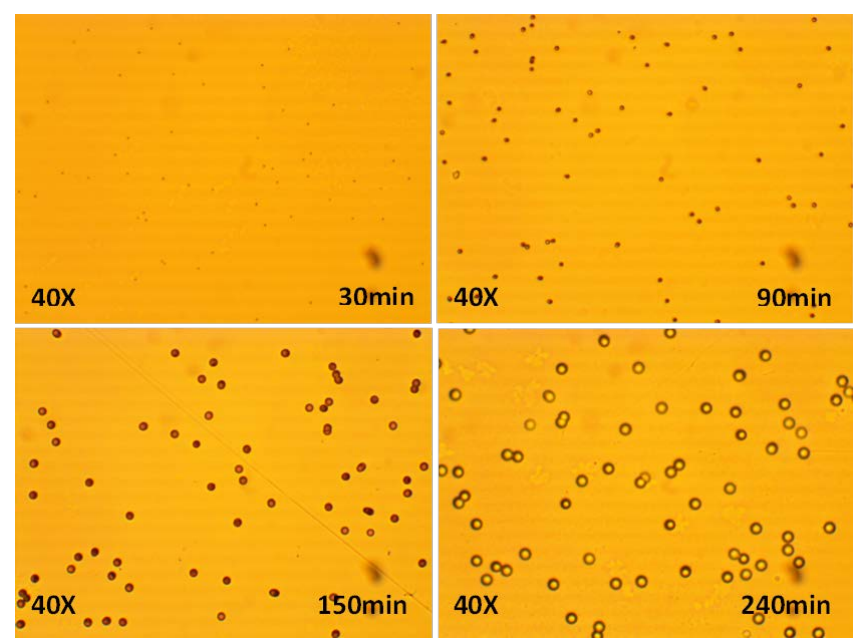

Figure 2. Views of CR-39 detector etched chemically at (30, 90, $150,240)$ minutes with water bath.

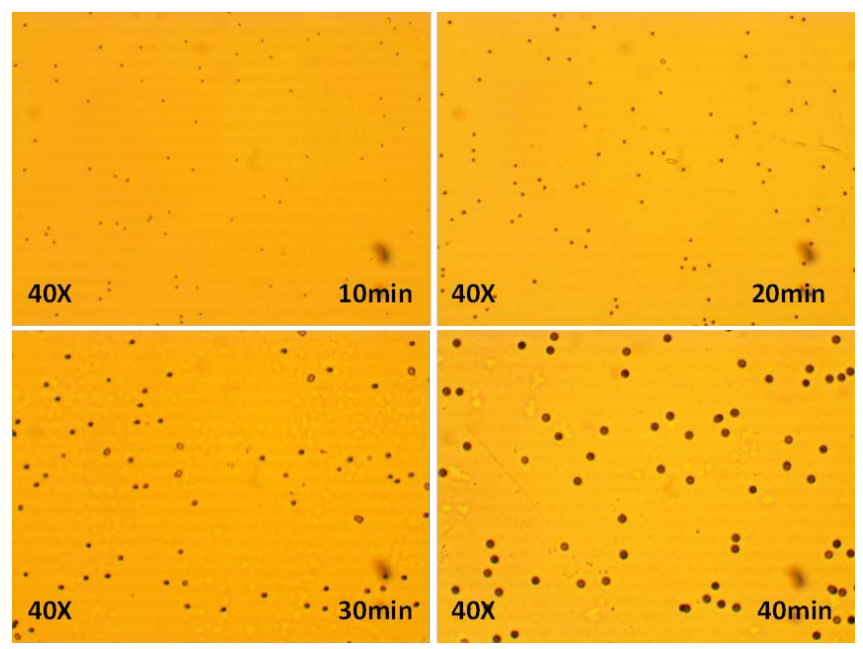

Figure 3. Views of CR-39 detector etched chemically at (10, 20, $30,40)$ minutes with microwave device.

\subsubsection{Chemically Etching with Ultrasound Device}

The CR-39 track detectors are etched for different Progressive times with an interval of (30 minutes) between them, in order to reach the optimum time. Eight times are used $(30,60,90,120,150,210,240)$ minutes to achieve this. The applied etching times and the track densities appear in the detectors for the three times of irradiation, in addition to the maximum and average of the track densities are illustrated in Table 3.

The increasing of the track densities with the developing of the latent tracks and the enlarging of them against the increasing of the etching time can be clearly observed in Figure 4.

\subsection{Calculations of Chemical Etching Parameters}

The Five chemical etching parameters of CR-39 detectors for the three chemical etching techniques (water bath, microwave and ultrasound) have been calculated. The bulk etch rate of the undamaged surface is calculated from equation (1), where $D$ in equation is the average diameter of the track, which is measured with the use of camera supplied with a software program, by taking the average of several tracks radius measured and then multiplying by two and substituting in the above equation for all our etching times.

Track etch rate or the etch rate along the latent track is calculated from the equation (2), where $V_{D}$ which is the diameter rate of the tracks were calculated from the slope of the relation $\left(V_{D}=\Delta D / \Delta t\right)$ between track diameters 


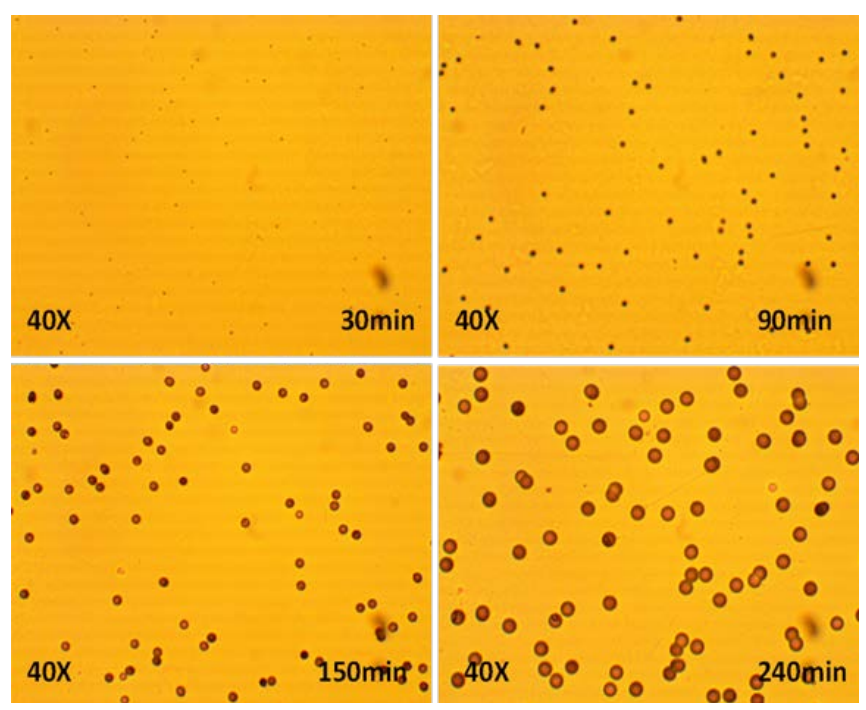

Figure 4. Views of CR-39 detector etched chemically at (30, 90, 150, 240) minutes with ultrasound device.

Table 3. Track densities in CR-39 track detector at the different doses and various etching times using ultrasound device.

\begin{tabular}{cccc}
\hline $\begin{array}{c}\text { Etching time } \\
(\mathrm{min})\end{array}$ & Track density $\left(\mathrm{no} / \mathrm{mm}^{2}\right)$ & \multicolumn{2}{c}{ Time of exposure to alpha source } \\
\cline { 2 - 4 } 30 & $(10 \mathrm{sec})$ & $(20 \mathrm{sec})$ & $(30 \mathrm{sec})$ \\
60 & 614 & 1212 & 1672 \\
90 & 658 & 1271 & 1874 \\
120 & 689 & 1267 & 2067.9 \\
150 & 757 & 1345 & 1975 \\
180 & 640 & 1265 & 1814 \\
210 & 672 & 1255 & 1790 \\
240 & 662 & 1204 & 1778 \\
Average & 638 & 1088 & 1721 \\
Max & 666.2 & 1239.5 & 1836.48 \\
\hline
\end{tabular}

and etching times. Figures 5-7 represent the slopes for Tables 1-3.

The five etching parameters $\left(V_{B}, V_{T}, V, \theta_{C}, \eta\right)$ are listed in Table 4 which represent the parameters for; CR-39 detector when irradiated with alpha particles, at the three using devices (water bath, microwave, ultrasound) respective.

\section{Results and Discussion}

\subsection{Chemically Etching of CR-39 Detector Irradiated with Alpha}

From Tables 1-3 we can plot Figures 8-10 which showing:

1) The track density is increased with the increasing of the irradiation time, because the increasing of the alpha radiation dose.

2) The etching times are being reduced with the increasing of the radiation dose.

3) Tracks starting to develop with a considerable value (30 minute) when etching with water bath and ultrasound, but with a minimal time (10 minute) when etching with microwave because the additional effect of microwave radiation device. 


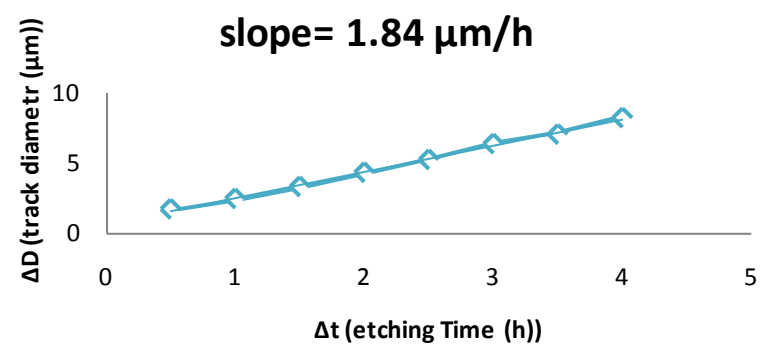

Figure 5. Slope between track diameter and etching time for CR-39 etched with water bath.

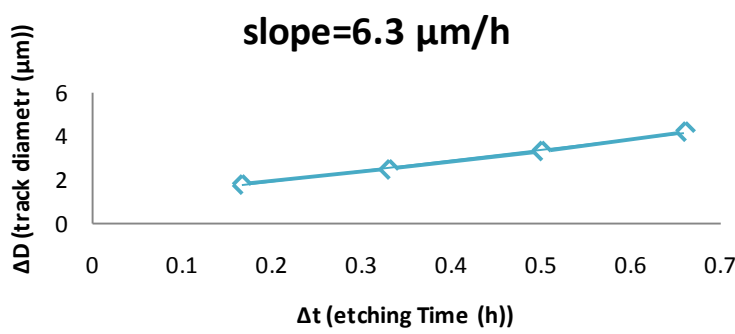

Figure 6. Slope between track diameter and etching time for CR-39 etched with microwave.

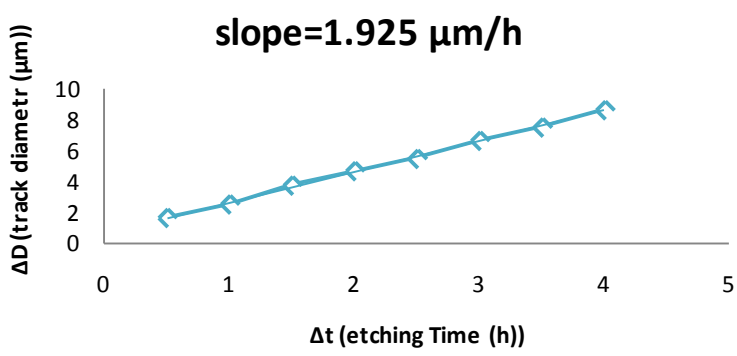

Figure 7. Slope between track diameter and etching time for CR-39 etched with ultrasound.

Table 4. Etching parameters of CR-39 detector irradiated with alpha.

\begin{tabular}{cccccc}
\hline Etching device & $V_{B}$ & $V_{T}$ & $V$ & $\theta_{C}$ & $\eta$ \\
\hline Water bath & 1.15 & 2.62 & 2.278 & 26.03 & 0.561 \\
Microwave & 4.00 & 9.5 & 2.375 & 24.9 & 0.58 \\
Ultrasound & 1.22 & 2.87 & 2.352 & 25.15 & 0.575 \\
\hline
\end{tabular}

4) The track density when etching with water bath is increased between the etching times (60 - 150 minute). After that the density begins to decrease because the tracks start to overlap each other's. For microwave the maximum values of the track density would appears at etching time range (20 - 30 minute). For ultrasound the maximum values of the track density would appears at etching time between (60 - 120 minute).

5) The average of the track density of the detectors etched with water bath is more than the average of the track density of the detectors etched with ultrasound.

6) The reason for the ups and down in the chart, the track density begins small number then increases and then decreases.

\subsection{Etching Parameters of the Tracks}

From Table 4 we can conclude the following points: 


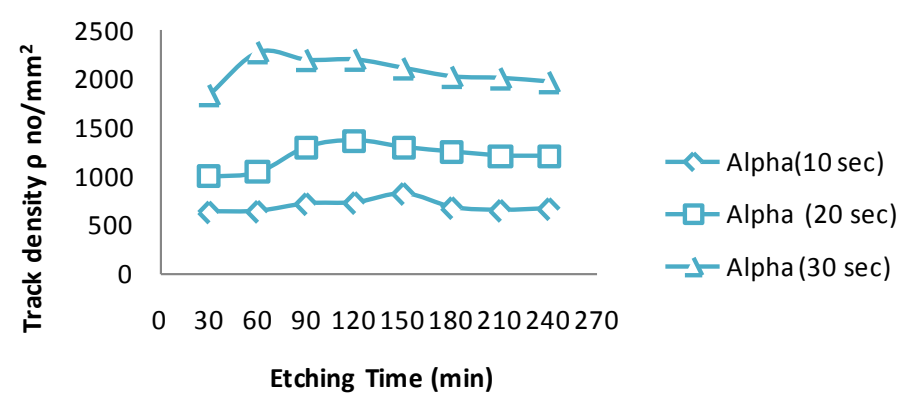

Figure 8. Track density against etching time for (CR-39) etched with water bath when irradiated at different doses.

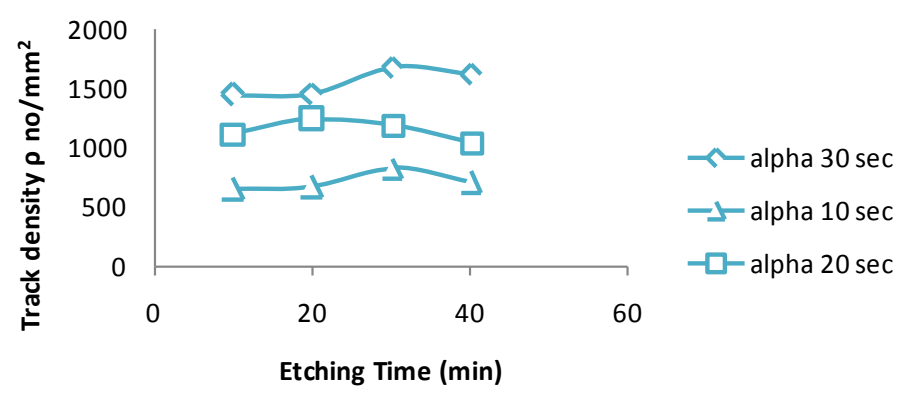

Figure 9. Track density against etching time for (CR-39) etched with microwave when irradiated at different doses.

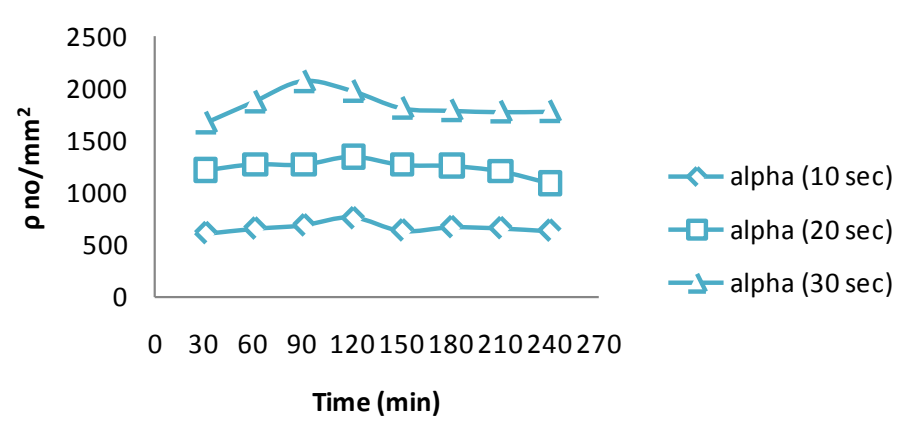

Figure 10. Track density against etching time for (CR-39) etched with ultrasound when irradiated at different doses).

1) The etching rate ratio $(V)$ which represent the speed of etching track $\left(V_{T}\right)$ relative to the speed of etching surface $\left(V_{B}\right)$ have the maximum value when etching in microwave, ultrasound and water bath devices respectively. This may be related to the interaction between the microwave radiation and the etching solution during the etching time.

2) The critical angle has the minimum value when etching with microwave than the value when etching with water bath or ultrasound devices. This value can be considers the optimum value because the decreasing of this angle leads to increasing the number of the developed tracks.

3) The registration efficiency for the detectors etched with microwave device is greater than that etched with water bath and ultrasound device.

\section{Conclusions}

1) The images of tracks viewed in the detectors irradiated for 20 second more clearly because they don't overlap, so it can be considered the optimum irradiated time in our research.

2) The etching with microwave is faster than that with other techniques.

3) The etching time will decrease with the increase of alpha energy. 
4) The track density increases with the time of exposure.

5) The average of the track densities in all etching techniques is converged somewhat.

6) The greatest etching rate ratio $V$ observed when etching with microwave.

7) The etching efficiency when etching with microwave is greater than that etched with water bath or ultrasound because their critical angle is less.

\section{References}

[1] Fleischer, R.L., Price, P.B. and Walker, R.M. (1965) Solid-State Track Detectors: Applications to Nuclear Science and Geophysics. Annual Review of Nuclear Science, 15, 1-28. http://dx.doi.org/10.1146/annurev.ns.15.120165.000245

[2] Tripathy, S.P., Kolekar, R.V., et al. (2010) Microwave-Induced Chemical Etching (MCE): A Fast Etching Technique for the Solid Polymeric Track Detectors (SPTD). Nuclear Instruments and Methods in Physics Research A, 612, 421426. http://dx.doi.org/10.1016/j.nima.2009.10.096

[3] Dazhuang, Z. (2010) Methods Using CR-39 Plastic Nuclear Track Detectors in Radiation Research. Nova Science Publishers, Inc., New York, 10.

[4] Durrani, S.A. and Bull, R.K. (1987) Solid-State Nuclear Detection; Principles, Methods, and Applications. Pergamon Press, UK.

[5] Shahid, M. (2007) Improvements and Calibration of Nuclear Track Detectors of Rare Particle Searches and Fragmentation Studies. University degli Bologna, 12.

[6] Nada, F. (2014) Evaluation of the Uranium Concentrations in Human Tissues Samples by Fission Fragments Induced Using CR-39 Nuclear Track Detector. IJAIEM, 3, 98-104.

[7] Hassan, A.Y. (2015) Studying the Radioactivity in Two Human Organs Breast and Uterus Using CR-39 and Lexan Track Detectors. M.Sc. Thesis, University of Al-Mustansiriyah.

[8] Pandey, A.K., Kalsi, P.C. and Iyer, R.H. (1998) Effects of High Intensity Ultrasound in Chemical Etching of Particle Tracks in Solid State Nuclear Track Detectors. Nuclear Instruments and Methods in Physics Research B, 143, 393-399. http://dx.doi.org/10.1016/S0168-583X(97)00735-0

[9] Al-Niaemi, S.H.S. (2014) Effects of Ultrasound in Etching and Detecting Parameters of CR-39 Detector. Jordan Journal Physics, 7, 35-42. 